Thomas Waitz

\title{
MECCA-learn: A community based collaborative Course Management System for media-rich Curricula in the \\ Film Studies
}

DOI

https://doi.org/10.25365/phaidra.22

Original

Thomas Waitz: »MECCA-learn: A Community Based Collaborative Course Management System for Media-Rich Curricula in the Film Studies «, in: R.W.H. Lau/Q. Li et al. (Hg.): Advances in Web-Based Learning (=Lecture Notes in Computer Science 3583). Berlin/Heidelberg: Springer 2005, S.131-152 (zusammen mit Marc Spaniol, Ralf Klamma).

Kontakt

t.waitz@univie.ac.at

Hinweis

Diese Textfassung weicht in geringfügigen Details von der Druckfassung ab.

Thomas Waitz

http://www.thomaswaitz.at/

ORCID https://orcid.org/0000-0002-0137-515X

\section{cc) creative}

Dieses Werk ist unter Creative Commons Namensnennung - Keine kommerzielle Nutzung Keine Bearbeitungen 4.0 International (CCBY-NC-ND 4.0) lizenziert. Um die Lizenz anzusehen, gehen Siebitte zu: https://creativecommons.org/licenses/by-nc-nd/4.0/legalcode.de 


\title{
MECCA-learn: A community based collaborative Course Management System for media-rich Curricula in the Film Studies
}

\author{
Marc Spaniol ${ }^{1,3}$, Ralf Klamma ${ }^{1,3}$, and Thomas Waitz ${ }^{2,3}$ \\ 1 RWTH Aachen University, Informatik V, Ahornstr. 55, D-52056 Aachen, Germany \\ \{mspaniol|klamma\}@cs.rwth-aachen.de \\ 2 Institute for Media Studies, Ruhr-Universität Bochum, Germany \\ thomas.waitz@ruhr-uni-bochum.de \\ 3 Forschungskolleg "Medien und kulturelle Kommunikation", Universität zu Köln, \\ Bernhard-Feilchenfeld-Str. 11, D-50969, Germany
}

\begin{abstract}
Even with a large number of course management systems at the market and already established in some universities, impact of these systems on the curricula design in the humanities and the cultural sciences is still marginal. Instead of complaining about the reluctance against technology in the non-technical disciplines we try to contribute to establishing an e-learning culture in these faculties. First we introduce on the one hand existing theories on knowledge creation and social learning in information systems research and on the other hand mediaspecific theories developed in the humanities. By combining these both approaches we achieve a deeper understanding of the underlying scientific methodologies and information systems' needs. Then we analyze the existing course management systems in the humanities and the cultural sciences with respect to these requirements. Our study indicates that no course management system covers all of these needs. Thus, we introduce MECCA-learn on top of the Movie E-learning Combination and Categorization Application (MECCA) as a basic course management system. It is deployed for a web based community of learners in a media-rich curriculum that allows a tight interaction between multimedia artifacts, their situational context and discourses on them.
\end{abstract}

\section{Introduction}

Course management systems like Blackboard and WebCT have been introduced into universities in recent years and reshaped university teaching and learning in many aspects. These systems help to build up reusable repositories of learning materials with support tools for teachers (e.g. curriculum design, course delivery, administration) and students (e.g. productivity, communication, involvement) with predictable institutional and infrastructural costs. Although these systems are in general able to support curricula in the humanities and the cultural sciences, most of the administrated courses in universities at the moment are originated from natural sciences, engineering, economics, and not surprisingly educational psychology. Universities, which use the current course management systems report a lack of acceptance in user communities of the 
humanities [5,33]. The authors identify at least two reasons. First, there seems to be a general reluctance to use computer based systems. This might be true for some of the researchers and teachers in the humanities, but our experience shows that the majority are fascinated by possibilities of new technology as long as they match their research and teaching needs. Second, existing systems might be designed too narrowly. Thus, a simple transfer of information system (IS) metaphors [9] (e.g. workflow management [26], knowledge management [22], organizational memory [30]) successful in other domains might not be successful in general. Especially the humanities require a particularly sensitive design of information systems [7] that fits into their scientific methodology. For that reason, we have developed several information systems in tight cooperation with our colleagues from the cultural sciences and the humanities $[15,29,16]$ within the collaborative research center on "Media and Cultural Communication".

In this paper we present MECCA-learn as a hypermedia course management system for media-rich curricula in the humanities and cultural sciences. Next, we introduce a framework for media-centric community learning in these disciplines. Then we compare some of the existing course management systems with respect to their suitability for the needs of learner communities in the humanities and the cultural sciences. Afterwards, we present MECCA-learn and a case study conducted in a community of practice in the film studies. The paper finishes with conclusions and an outlook on further research.

\section{Media-centric learning communities in the humanities and the cultural sciences}

Learner communities in the humanities and the cultural studies are coined by the discoursive nature of functioning within the humanities in general. This attitude of collaborating, thinking, working and thus learning is different from the common attitude in engineering or the natural sciences. Consequently, the needs of learner communities vary with respect to the support they need from course management systems. According to Snow [28], the type of knowledge creation and exchange in learning can be divided into to two styles. First, the "linear type' of learning that is goal-oriented and transmission-centered. This means, old knowledge is replaced by new one as soon as it appears. Second, there is a 'non-linear type' of learning. Here, old knowledge isn't replaced but kept in the repository for a potential later usage. This style is (multi-) media-centric and resembles the functioning in the humanities. The rich media used in the discourse heavily depend on the situational context or are part of the discourse itself. Studies in organizational theory, linguistics, and experimental psychology $[6,10]$ generated similar results showing that the underlying knowledge generating systems (e.g. the human brain, the organization, the discourse) are not media independent. Thus, hypermedia metaphors are ideal to link the media to the knowledge system, and to express dependencies between them. Here, it is possible to capture the discourses about media by simultaneously providing a high degree of collaboration possibilities. Therefore, a joint (intellectual property protecting) multimedia repository is needed to share and exchange content. 


\begin{tabular}{|c|c|c|c|}
\hline $\begin{array}{c}\text { Activities in } \\
\text { learning communities }\end{array}$ & $\begin{array}{c}\text { Knowledge conversions by } \\
\text { Nonaka \& Takeuchi [22] }\end{array}$ & $\begin{array}{c}\text { Media specific } \\
\text { operations }\end{array}$ & $\begin{array}{c}\text { Operation } \\
\text { type }\end{array}$ \\
\hline $\begin{array}{c}\text { Task creation } \\
\text { Hypermedia document editing }\end{array}$ & $\begin{array}{c}\text { implicit } \rightarrow \text { explicit } \\
\text { Externalization }\end{array}$ & Transcription & Human \\
\hline $\begin{array}{c}\text { Multimedia management } \\
\text { Metadata management }\end{array}$ & $\begin{array}{c}\text { explicit } \rightarrow \text { explicit } \\
\text { Combination }\end{array}$ & Transcription & (Semi-) Automatic \\
\hline $\begin{array}{c}\text { Task assignment } \\
\text { Media centric presentation }\end{array}$ & $\begin{array}{c}\text { explicit } \rightarrow \text { implicit } \\
\text { Internalization }\end{array}$ & Addressing & (Semi-) Automatic \\
\hline $\begin{array}{c}\text { Discourses } \\
\text { Collaboration }\end{array}$ & $\begin{array}{r}\text { implicit } \rightarrow \text { implicit } \\
\text { Socialization }\end{array}$ & Localization & Human \\
\hline
\end{tabular}

Table 1. Theoretical framing of activities in learning communities

Thus, the question is: How can we integrate these functional requirements into a media-rich course management system (CMS) suitable for university-wide or even cross-university e-learning? The key point is simple: We have to provide an option for learners to hold media-centric discourses within courseware management systems. Consequently, the gap between a strictly sequential course organization and informal discourses will be bridged.

In our research center an operational media-theory has been developed that helps to understand the discursive nature of knowledge creation in the humanities. In order to transfer this theory on appropriate information system metaphors we have combined this theory with well known theories in information systems on knowledge creation (Nonaka and Takeuchi [22], Polanyi [23]) and social learning processes (Wenger [32]). This combination helped us to identify relevant activities performed by humans and machines in the information system. Based on the following three media operations $[14,10]$ the importance of the media in the discourses becomes visible:

- Transcription is a media dependent operation - either (semi-)automatic by the IS or manual by a human - that makes media collections more readable.

- The term of (re-) addressing describes an operation that intends to stabilize and optimize the presentation of content.

- Localization means an adaptation of global media into local practices.

Table 1 synthesizes knowledge conversions and media specific operations as a framework for media centric community learning process in the humanities. It comprises four distinct steps in a knowledge creation process and indicates whether the operation is performed by an individual (human) or by a machine (automatic). These successive steps may be repeated infinitely often, creating an often described continuous knowledge creation spiral. It oscillates between individuals and bigger social entities on the one axis and between implicit and explicit knowledge on the other axis. This knowledge creation process is called a learning process accordingly. The first step which implements collaboration possibilities is assigning task within learning community. It can be done by a tutor or a learner and is a transcription process. Therefore, a topic related to a certain media set of the multimedia repository is specified. In parallel, a new hypermedia document is created. Then, the task is processed automatically by the machine and descriptions compliant to the MPEG-7 multimedia 
metadata standard [13] are generated. Next, a media-centric addressing takes place when either multimedia artifacts are explored or hypermedia documents are presented. The cycle is closed, when discourses about hypermedia documents take place or the documents themselves initiate a new task. Thus, content of the information system has been adopted within the learning community by localization and the process may start anew. In the next section, we will give an overview on CMS in use and discuss whether these systems comply with the aforementioned needs of learning communities in the humanities.

\section{Analysis of existing Course Management Systems}

There are many tools dealing with courseware management and e-learning in general. They vary from simple web based training tools to high level all-in-one systems combining workspaces, forums and learning materials. We now present related work in detail but confine the overview to those systems that are specially designed for use in academic education.

MIT OpenCourseWare (OCW) [19] is a free and open educational resource addressing faculty, students, and self-learners around the world. It is used for publication of MIT course materials and doesn't require any registration. Thus, MIT OCW offers courseware such as syllabi, readings, and sample solutions. Although it contains many MIT courses of various curricula, it isn't degree- or certificate-granting and doesn't provide access to MIT faculty. Its strength is its public accessibility and the wide range of materials available. However, it doesn't offer any specific means for transcription and localization among learners.

WebCT is probably the most widespread commercial CMS [25]. It offers a broad bandwidth of teaching and learning tools for development, delivery, and management of courses. The system is login based and offers students a possibility of learning at different levels. Addressing of e-learning content takes place via a shared workspace, but tasks can be assigned by tutors only. In addition, multimedia exploration is not central, but only a side effect. Collaboration and discourses are supported by forums, chat, or email. Access rights to these localization facilities depend on the user's rights. Transcription is based on SCORM [1], but there is no support to create designated hypermedia documents.

AIMS is a knowledge-based learning-content management system designed at Eindhoven University in the Netherlands to support both instructors and students [2]. Its intention is to provide an easy-to-use system that can either complement existing course delivery systems or can be used as a standalone learning content management tool. Thus, for addressing of e-learning content it enables tutors to author adaptive course sequencing driven by SCORM. Transcription is supported by LOM compliant management of teaching resources. However, support of localization among learners is not mentioned.

CLIX is a login based commercial course management system [12]. It fulfils the requirements of SCORM transcription. For addressing issues it contains several e-learning and course management tools that have most of their functionality restricted to tutors. E-learning content comprises web based tests, assessment tests, skill and competency management, and a virtual classroom for content 


\begin{tabular}{|c|c|c|c|c|c|c|c|c|c|}
\hline & MIT OCW & WebCT & AIMS & CLIX & Moodle & Blackboard & Wiki & $\mathrm{BSCW}$ & $\begin{array}{l}\text { MECCA- } \\
\text { learn }\end{array}$ \\
\hline Access & Public & Via Login & Via Login & Via Login & Via Login & Via Login & $\begin{array}{l}\text { Open or } \\
\text { via Login }\end{array}$ & Via Login & Via Login \\
\hline Product type & Educational & Commercial & Educational & Commercial & Educational & Commercial & Open source & \begin{tabular}{|c|}
$\begin{array}{c}\text { Educational } \\
\text { or } \\
\text { Commercial }\end{array}$ \\
\end{tabular} & Educationa \\
\hline \begin{tabular}{cc} 
(Multimedia) \\
\hdashline $\bar{y}$ \\
Metadata \\
Standard
\end{tabular} & No & SCORM & $\begin{array}{l}\text { SCORM, } \\
\text { LOM }\end{array}$ & SCORM & No & No & No & No & MPEG-7 \\
\hline 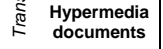 & No & No & No & No & No & No & Yes & No & Yes \\
\hline $\mid \begin{array}{cc}\text { of } & \text { Flexible task } \\
\text { w } & \text { assignment }\end{array}$ & No & $\begin{array}{l}\text { Only for } \\
\text { tutors }\end{array}$ & $\begin{array}{l}\text { Only for } \\
\text { tutors }\end{array}$ & $\begin{array}{l}\text { Only for } \\
\text { tutors }\end{array}$ & $\begin{array}{l}\text { Only for } \\
\text { tutors }\end{array}$ & $\begin{array}{c}\text { Workflows } \\
\text { available }\end{array}$ & No & $\begin{array}{c}\text { Workflows } \\
\text { available }\end{array}$ & Yes \\
\hline 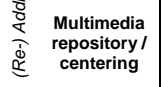 & $\begin{array}{l}\text { Only for } \\
\text { download }\end{array}$ & $\begin{array}{c}\text { Yes, but } \\
\text { multimedia } \\
\text { exploration } \\
\text { isn't central }\end{array}$ & No & $\begin{array}{l}\text { Only for } \\
\text { download or } \\
\text { via email }\end{array}$ & $\begin{array}{l}\text { Upload only } \\
\text { for } \\
\text { assignments } \\
\text { or via email }\end{array}$ & $\begin{array}{c}\text { Yes, but } \\
\text { multimedia } \\
\text { exploration } \\
\text { isn't central }\end{array}$ & $\begin{array}{l}\text { Yes, but } \\
\text { multimedia } \\
\text { exploration } \\
\text { isn't central }\end{array}$ & $\begin{array}{c}\text { Yes, but } \\
\text { multimedia } \\
\text { exploration } \\
\text { isn't central }\end{array}$ & Yes \\
\hline \begin{tabular}{cc}
$\delta$ & Discourse \\
\hdashline $\bar{\delta}$ & support
\end{tabular} & No & \begin{tabular}{|c|} 
Forum, \\
Chat, Email
\end{tabular} & ??? & $\begin{array}{c}\text { Forum, } \\
\text { Chat, Email }\end{array}$ & $\begin{array}{c}\text { Forum, } \\
\text { Chat, Email }\end{array}$ & $\begin{array}{c}\text { Forum, } \\
\text { Chat, Email }\end{array}$ & Yes & Notes, Email & $\begin{array}{c}\text { About any } \\
\text { item }\end{array}$ \\
\hline 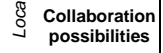 & No & $\begin{array}{c}\text { Based on } \\
\text { user groups }\end{array}$ & ??? & $\begin{array}{l}\text { Based on } \\
\text { user groups }\end{array}$ & $\begin{array}{l}\text { Based on } \\
\text { user groups }\end{array}$ & $\begin{array}{l}\text { Based on } \\
\text { user groups }\end{array}$ & Unlimited & $\begin{array}{c}\text { Based on } \\
\text { user groups }\end{array}$ & $\begin{array}{l}\text { Based on } \\
\text { user groups }\end{array}$ \\
\hline
\end{tabular}

Table 2. Comparison of course management systems with respect to their support in transcription, localization, and (re-) addressing operations

presentation via browser. CLIX also includes communication tools for localization, such as forum, chat, or email.

Moodle stands for Modular Object-Oriented Dynamic Learning Environment [20]. It's considered to be the most prominent open source courseware system. Moodle is login based and offers tutors task assignment tools for addressing. For that purpose, Moodle offers three different categories of assignments: Weekly, topics, and social. Students are not allowed create assignments themselves but may upload their completed assignments or share materials via email. Based on the group rights localization is fostered via forums, chat, or email conversations. However, Moodle doesn't support transcription elements yet.

The mentioned systems so far mostly emphasize strict course organization, but don't facilitate in general the community wide addressing of multimedia artifacts. In addition, localization by means of collaboration among learners and discourses is mostly shifted to proprietary tools such as emails, etc. Thus, discourses and media are "separated", which leads to problems in media-centric studies. This deficit is tackled by the systems we will discuss next.

Blackboard Academic Suite ${ }^{\mathrm{TM}}$ is a commercial login based e-learning environment to support widely diverse constituencies and education missions [4]. For addressing it offers a repository to share content of various file types without centering the media used. Additionally, it contains workflow facilities. Blackboard also comprises communication tools for localization, such as forum, chat, or email. Even though it offers almost all features to support learning processes in the humanities, its main drawbacks are that it doesn't support transcription elements up to now and that it lacks media centering in addressing.

Wikis are in Ward Cunningham's description "the simplest online database that could possibly work". A Wiki is an open source web based collaborative content 
management system that is also suitable for e-learning [31]. The strength of a Wiki is its openness in localization. Collaboration is almost unlimited and discourses may take place about any item. Transcription benefits from this concept,too. Hypermedia documents can be created by linking discourses with the underlying media, but metadata standards are not yet supported. In terms of addressing Wikis are suitable to manage multimedia content, but multimedia exploration is not central. Moreover, dedicated task management isn't supported. BSCW (Basic Support for Collaborative Work) serves as a collaborative community content management system on the web [17]. It is a commercial tool also providing free of charge usage for educational institutions. Its localization features are very advanced for media-centric discourses and collaboration. Moreover, for addressing it offers support for versatile media formats to be shared as well as tasks to be defined within workflows. Nevertheless, multimedia exploration is not central, but only a side effect. Transcription is not supported, since collaboratively created documents are not suited to contain hypermedia.

Apart from the systems mentioned before, there are specific networking tools for course presentation and streaming of lectures. These are e.g. Edutella [21], Prolearn TV [27], or Isabel [24]. Since they focus on either presentation or management of e-learning content they haven't been discussed in detail. Table 2 condenses the previously mentioned CMS with respect to operations needed in media-centric curricula. For the sake of comparability, the features of MECCAlearn, which will be introduced in the following chapter, are included as well.

\section{MECCA-learn}

In order to make e-learning successful among the communities of learners in the cultural sciences we provide them with a specially designed multimedia screening and classification application called MECCA (Movie E-learning Combination and Categorization Application) [16]. It is based on the Virtual Entrepreneurship Lab (VEL), which has been successfully applied in online entrepreneurship training, integrating ideas from "Berliner sehen" [8]. MECCA targets a multidisciplinary research community in a project of the film studies. The community is spatially distributed between the universities of Bochum and Bonn as well as the research center in Cologne. Its members have diverse backgrounds of education, e.g. film studies, history of art, graphical design and are on diverse levels of professionalism, i.e. full professors, research assistants, and students. Together, they share a joint enterprise within a research project on facial expressions in movies. MECCA allows the analysis of multimedia artefacts, the creation of temporal decompositions and to (re-) classify artefacts according to the user's needs. Thus, it supports e-learning on the research level only. That means, MECCA (figure 1) is most suitable for researchers to collaborate in a distributed setting, but it does not focus on academic teaching. Therefore, the existing research oriented MECCA system has been further developed to suit the needs of media-rich curricula in the film studies. Dedicated features for course management and support of hypermedia documents have been added. With these features, it is now possible to represent discoursive acts within the CMS as in real on campus. By example of a task editing, we now present the key features of MECCA-learn. 


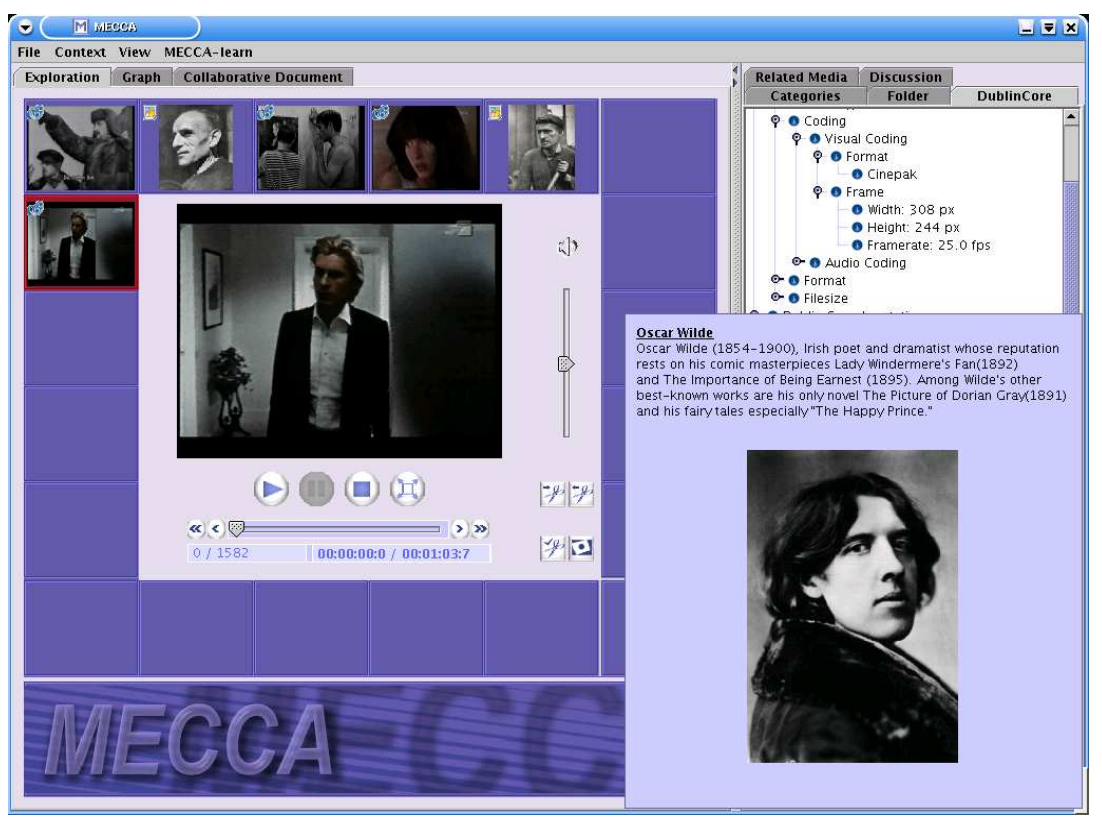

Fig. 1. MECCA user interface

The learning process starts with a human transcription by creating a task. In this aspect, MECCA-learn allows a loose structuring of courses and their decomposition into subtasks by a flexible task arrangement system. Due to the system's collaboration possibilities a task might be created by anyone and it is left to the user, to contribute to it or not. Because of the media-centering in the film studies the next step is the attribution of rich media to a task. This is accomplished by a reference to the respective medium within the metadata file of the task. For the sake of usability, a consecutive (semi-) automatic transcription step takes place. Here, information is captured by a concatenation of the basic element set of Dublin Core [3] and audio visual descriptors of MPEG-7. Since Dublin Core is popular in the humanities, but most suitable for print media, we have selected an excerpt of the extensive MPEG-7 multimedia metadata standard that allows a detailed metadata annotation of media as well as their temporal decompositions. MPEG-7 metadata about technical aspects of the medium such as visual encoding, frame rate, color space, etc. are extracted automatically by MECCA-learn. Additional information about the medium such as title, creator, etc. can be added manually by the users. In addition, there is an affiliated FTP-server serving as a collaborative multimedia repository. After completion, the resulting task and its affiliated media set are stored on the server. Then the task can be seen by all the users that have been assigned to it.

The e-learning process continues in an addressing of the assigned tasks and their media-centric presentation. Figure 2 shows the tasks assigned to a user. For the sake of usability, a graph representation can be selected in order to get an overview on the task dependencies. Since we allow the decomposition of 


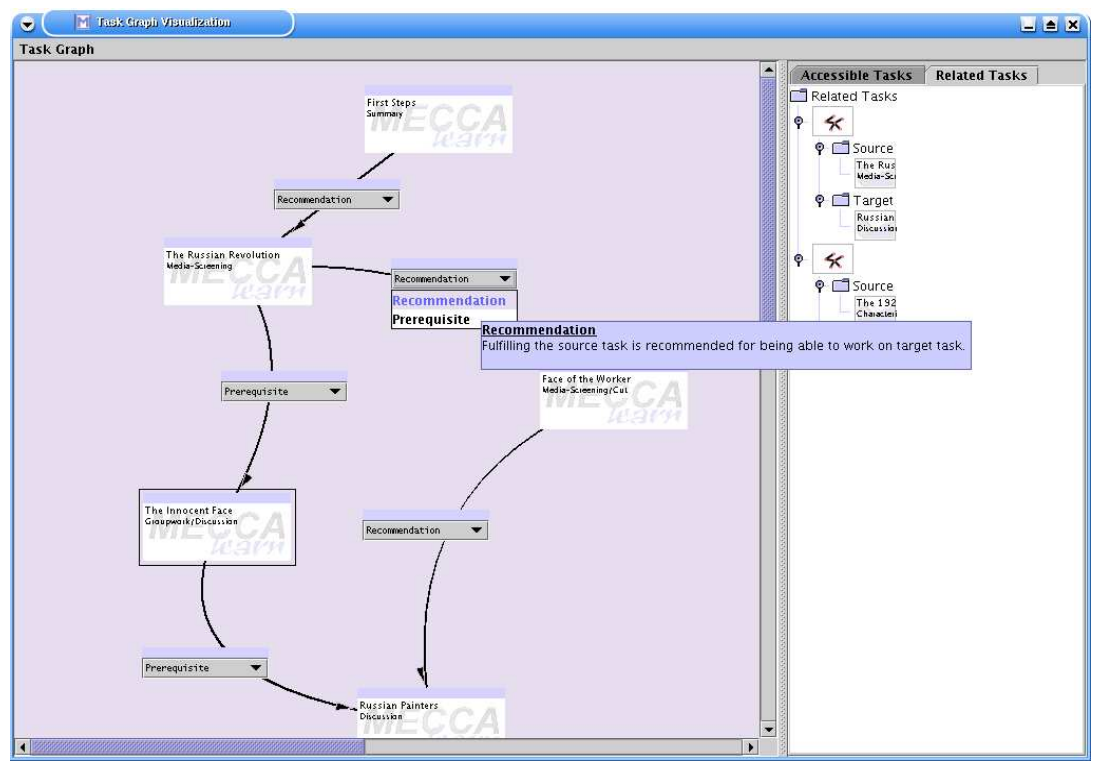

Fig. 2. Tasks assigned to a community member visualized as a graph

tasks into subtasks, dependency types of tasks can be specified and visualized. When passing over the task, a tool-tip highlights additional information about the task, its creator and the date of creation. Since tasks might be assigned to an individual or a group, students have the option to collaborate and edit the related hypermedia documents.

The final step in the e-learning process takes place by localization. This is reflected in the collaborative hypermedia documents as well as the discourses about them. Figure 3 shows a collaborative hypermedia document that has been created for a particular task. The document is split into two sections. On the left hand side, the document iself is displayed. It consists of "containers" that might be filled with text, media, categorization elements, and media dependency graphs. All this information is stored as a MPEG-7 compliant graph description. Since the graph description is kept flexible, the references can be of different type and can be freely rearranged at any point in time. Additionally, the document history can be traced back. For that reason, every "container" is tagged upon creation, edition, or deletion. Hence, documents can easily be restored by selecting the appropriate version of a particular container. The right hand side of the interface contains metadata about the collaborative document and its embedded rich media. The pane displays ongoing discourses as well as information about the media themselves. Finally, the hypermedia document or the task might be refined or newly created. Thus, closing the e-learning process and creating a continuous knowledge creation cycle.

From the technical side, MECCA-learn has been implemented as a Java application. Thus, it is platform independent which is of great importance, since our learning community in the humanities uses both MS Windows and Apple 


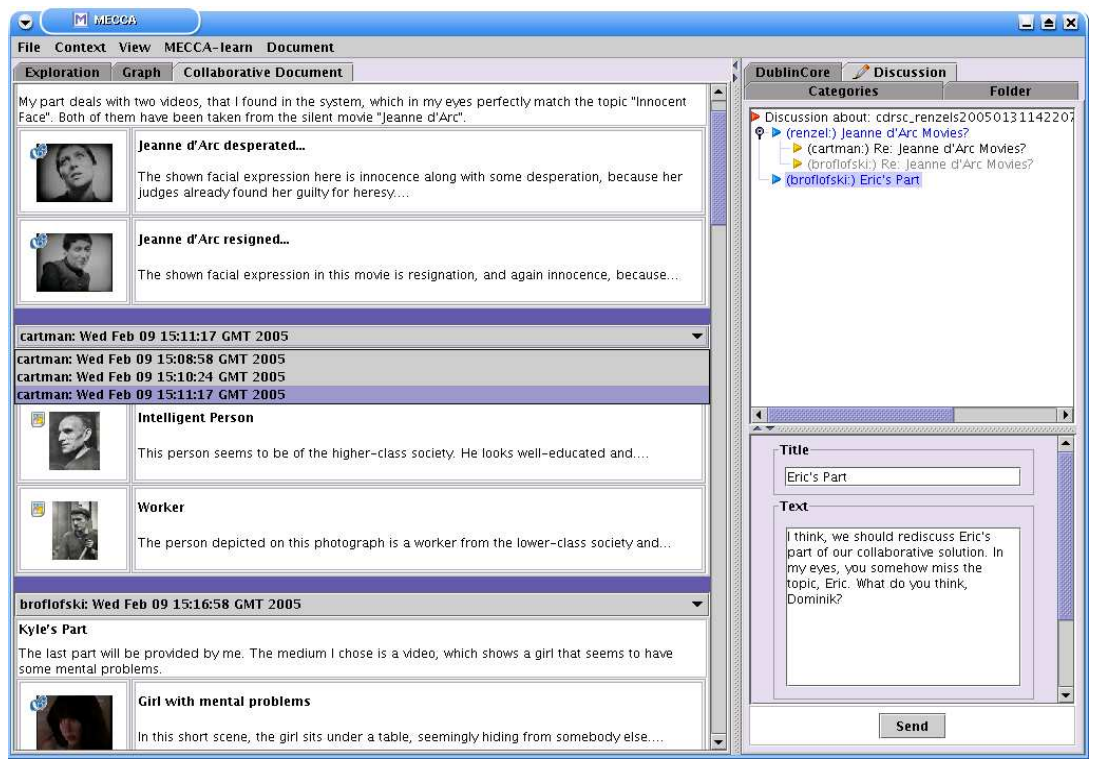

Fig. 3. A collaboratively created hypermedia document

computers. On the server side, we have set up an eXist XML database [18] for the storage of the MPEG-7 metadata. All the content of MECCA-learn is stored compliant to MPEG-7. For the sake of manageability the documents of MECCAlearn are decomposed into several fragments (cf. figure 4). The core document is a so called MECCA-learn "task", interrelated with metadata files about "media". In order to express dependencies between "tasks" in case they exist they are referenced by MECCA-learn "task relationships" files. The MECCA-learn "task" element itself refers to potentially many MECCA-learn "media" and MECCAlearn "hypermedia" files. While the "media" files are used to link the "tasks" with the contained media set, the "hypermedia" file(s) contains the "task's" composition. Since the composition of the "hypermedia" file is a media centric process, it may also contain media itself. Consequently, the "hypermedia" file

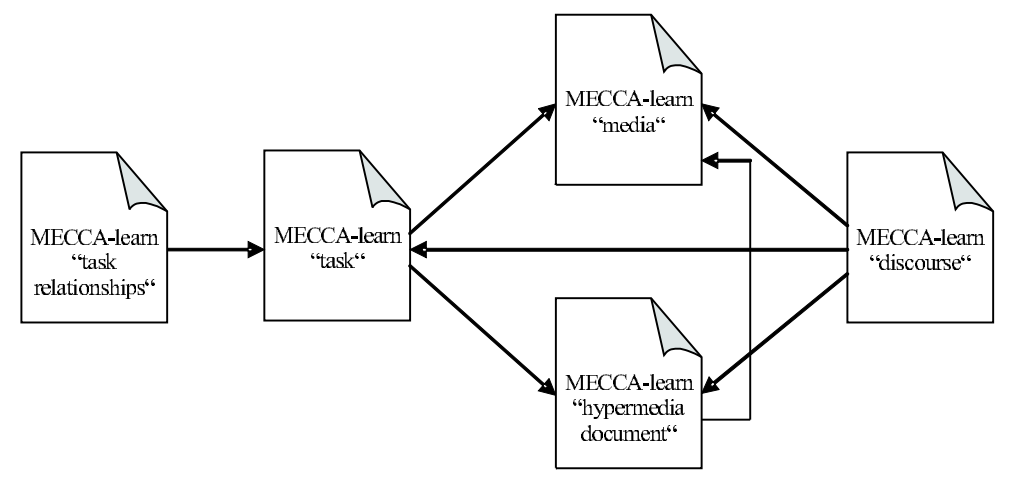

Fig. 4. Structural decomposition of tasks and their interdependencies in MECCA-learn 
may also contain references to "media" files. Finally, there is the "discourse" document type in MECCA-learn. "Discourses" may be used to link them with tasks, hypermedia documents, and media. They are a central element used for discussion about any element type in MECCA-learn. Summarizing, MECCA-learn is an open and collaborative CMS that ranges from simple course organization up to discourse and complex collaboration support via hypermedia documents between students and instructors in media-rich curricula.

\section{Conclusions \& Outlook}

Open CMS for university-wide or even cross-university e-learning in the humanities are still in infancy. Yet, web hosting of learner communities on basis of multimedia repository technologies is promising. Additionally, interleaving of media and their compositions by means of hypermedia is an important step facilitating media-rich curricula. We compared different selected course management systems already established in university teaching or propagated by research initiatives in e-learning. The results led to the development of a course management system called MECCA-learn. In our case study we demonstrated the usefulness of MPEG-7 as a metadata language for e-learning in media-rich curricula. Hence, the interrelation of collaborative hypermedia artifacts and media centric tasks make course management in the humanities more authentic, transparent, and flexible. In making such environments compatible to MPEG-7, the maturity of digital media management increases.

In the scope of the graduate course "pathos \& passion" (english translation) at Ruhr-Universität Bochum, MECCA-learn is currently being evaluated. About twenty students use MECCA learn frequently as part of their curriculum. In the scope of their studies, they use MECCA-learn to take video screenings, share media collections, analyze media dependencies and create hypermedia documents out of them. Since the course has just begun and will last until the end of summer term 2005, the evaluation has not yet been completed. However, first feedback of students is very promising, in particular, related with the openness of MECCAlearn. Moreover, they enjoy using the system not in a subordinated learner's role but as an equal community member. On the data management level, the usage of MPEG-7 as framework for the description of e-learning content in mediarich studies is very promising. Due to the course's focus on media dependencies, MECCA-learn is able to capture all "low-level" technical information about media and combine them with "high-level" semantics. Although, main parts of the LOM [11] standard are already encapsulated within the MPEG-7 documents of MECCA-learn, compliance to LOM doesn't exist yet but is aspired in future versions. Thence, we research on a (semi-) automatic converter of e-learning content from LOM to MPEG-7. This will allow a seamlessly integration of learning materials already described by LOM into MECCA-learn.

Currently, we also do research on two other topics. The first issue aims at the analysis of intercultural aspects on learning. Here, the detection of disturbance patterns is of particular interest. Our aim is to extract constellations that are most likely subject to disturbances in the learning process. The second aspect focuses on a more artistic area of application. In cooperation with Nalin Sharda 
(Victoria University, Melbourne) we develop an application for Multimedia Inspired Story Telling (MIST). MIST concentrates on the creation of non-linear multimedia stories. Our task is to investigate the stories reception process and the factors leading to success or failure. Hence, we intend to use graph analysis tools to detect disturbance patterns in multimedia stories.

\section{Acknowledgements}

This work was supported by the German National Science Foundation (DFG) within the collaborative research centers SFB/FK 427 "Media and Cultural Communication", the SFB 476 "IMPROVE", and by the $6^{\text {th }}$ Framework IST programme of the EC through the NoE on Professional Learning (PROLEARN) IST-2003-507310. We'd like to thank our colleagues for the many discussions. In particular, we thank our student workers Dominik Renzel and Monika Pienkos for the implementation of MECCA-learn.

\section{References}

1. ADL Technical Team. SCORM conformance requirements version 1.2. http://www.adlnet.org/screens/shares/dsp_displayfile.cfm?fileid=1059, 2004.

2. AIMS Project. AIMS: Adaptive Information System for Management of Learning Content. http://www.win.tue.nl/ laroyo/AIMS/index.htm, October 92003.

3. ANSI/NISO Z39.85-2001: The Dublin Core Metadata Element Set. http://www.niso.org/standards/resources/Z39-85.pdf, September 102001.

4. Blackboard Inc. Blackboard Academic Suite ${ }^{\mathrm{TM}}$. http://www.blackboard.com/docs/AS/Bb_Academic_Suite_Brochure.pdf, 2004.

5. S. E. Carson. MIT OCW Program Evaluation Findings Report. http://ocw.mit.edu/NR/rdonlyres/3DFAB417-0966-4CC-8025-94F1991302F6/0/ Program_Eval_March_2004.pdf, 2004.

6. R. Daft and R. Lengel. Organizational informations requirements, media richness and structural design. Management Science, 32(5):554 - 571, 1986.

7. G. De Michelis, E. Dubois, M. Jarke, F. Matthes, J. Mylopoulos, K. Pohl, J. Schmidt, C. Woo, and E. Yu. Cooperative information systems: A manifesto. Technical report, Aachener Informatik-Bericht 96-21, RWTH Aachen, 1996.

8. K. Fendt. Contextualizing content. In M. Knecht and K. von Hammerstein, editors, Languages across the Curriculum, pages 201 - 223. National East Asian Languages Resource Center / Ohio State University, Columbus, 2000.

9. F. Flores, M. Graves, B. Hartfield, and T. Winograd. Computer systems and the design of organizational interaction. ACM Transactions on Office Information Systems, 6(2):153 - 172, 1988.

10. J. Fohrmann and E. Schüttpelz. Die Kommunikation der Medien. Niemeyer, Tübingen, 2004 (in German).

11. IEEE Learning Technology Standards Committee WG 12. Learning Object Metadata. http://ltsc.iee.org/wg12/, 2004.

12. imc. Advanced Learning Solutions. http://www.im-c.de/, 2005.

13. ISO. Information technology - Multimedia content description interface - Part 8: Extraction and use of MPEG-7 descriptions. Technical Report ISO/IEC TR 15938-8:2002(E), International Organization for Standardization, 2002.

14. L. Jäger and G. Stanitzek, editors. Transkribieren - Medien/Lektüre. Wilhelm Fink Verlag, Munich, 2002.

15. R. Klamma, M. Jarke, E. Hollender, and D. Börner-Klein. Enabling communities by constructed media: The case of a web-based study environment for a talmudic 
tractate. In J. Fong et al. Advances in Web-Based Learning, Proceedings of the First International Conference, ICWL 2002, Hong Kong, China, August 17-19, 2002, volume 2436 of LNCS, pp. 275-285, Berlin Heidelberg, 2002. Springer-Verlag.

16. R. Klamma, M. Spaniol, and M. Jarke. MECCA: Hypermedia Capturing of Collaborative Scientific Discourses about Movies. informing science. The International Journal of an Emerging Discipline, N. Sharda (Ed.): Special Series on Issues in Informing Clients using Multimedia Communications, 8:3 - 38, 2005.

17. K. Klöckner. Bscw - educational servers and services on the WWW. In Proc. of the International C4-ICDE Conf. on Distance Education and Open Learning "Competition, Collaboration, Continuity, Change", Adelaide, September 9-14, 2000.

18. W. Meier. eXist: An Open Source Native XML Database. In A. B. Chaudhri, M. Jeckle, E. Rahm, and R. Unland, editors, Web, Web-Services, and Database Systems, NODe 2002 Web and Database-Related Workshops, Erfurt, Germany, October 7-10, 2002, Revised Papers, volume 2593 of LNCS, pp. 169-183, Berlin Heidelberg, 2003. Springer-Verlag.

19. MIT. OpenCourseWare. http://ocw.mit.edu/index.html, 2005.

20. Modular Object-Oriented Dynamic Learning Environment (moodle). http://moodle.org/doc/, 2005.

21. W. Nejdl, B. Wolf, C. Qu, S. M. Decker, S., A. Naeve, M. Nilsson, M. Palmér, and T. Risch. EDUTELLA: A P2P networking infrastructure based on RDF. In Proceedings of the 12 $2^{\text {th }} W W W$ Conference, Honululu, May 2002, pp. 604-615, 2002.

22. I. Nonaka and H. Takeuchi. The Knowledge-Creating Company. Oxford University Press, Oxford, 1995.

23. M. Polanyi. The tacit dimension. Anchor Books, Doubleday\&Co., New York, 1966.

24. J. Quemada, G. Huecas, T. de Miguel, J. Salvachua, B. Rodriguez, B. Simon, K. Maillet, and E. Law. EducaNext: A Framework for Sharing Live Educational Resources with Isabel. In Proceedings of the $13^{\text {th }} W W W$ Conference, Education Track, New York, May 2004, pages 11 - 18, 2004.

25. G. Ronald. Introduction to WebCTs Features (CE v4). http://www.webct.com/service/ViewContent?contentID=18710281, 2005.

26. T. Schäl. Workflow Management Systems for Process Organizations, volume 1096 of LNCS. Springer, Berlin and Heidelberg, 1996.

27. P. J. Scott and K. Quick. Heroic failures in disseminating novel e-learning technologies to corporate clients: A case study of interactive webcasting. In Proceedings of the $4^{\text {th }}$ International Symposium on Information and Communication Technologies, Cape Town, South Africa, Jan 3-6, ACM Press, 2004.

28. C. P. Snow. The Two Cultures. Cambridge University Press, Cambridge, 1959.

29. M. Spaniol, R. Klamma, L. Springer, and M. Jarke. Aphasics' communities learning on the web. In W. Liu, Y. Shi, and Q. Li, editors, Advances in Web-Based Learning, Proceedings of ICWL 2004, Beijing, China, August 8-11, volume 3143 of LNCS, pages 277-285, Berlin Heidelberg, 2004. Springer-Verlag.

30. E. W. Stein and V. Zwass. Actualizing organizational memory with information technology. Information Systems Research, 6(2):85 - 117, 1995.

31. J. Wagstaff. Wikipedia: It's Wicked. The Wall Street Journal Online, Loose Wire, 2004. http://www.theproduct.com/6m105/readings/spring04/encyclopedia.pdf.

32. E. Wenger. Communities of Practice: Learning, Meaning, and Identity. Cambridge University Press, Cambridge, UK, 1998.

33. V. Zafrin. Teaching in the Digital Age and philosophical differences. http://www.brown.edu/Departments/Italian_Studies/vhl/archives/2005/01/21/ teaching-in-the-digital-age-and-philosophical-differences/, January 212005. 